\title{
Effect of two different nursing care approaches on reduction of breast engorgement among postnatal women
}

\author{
Tawheda Mohamed Khalefa El-Saidy ${ }^{1}$, Reda Mohamed-Nabil Aboushady *2 \\ ${ }^{1}$ Community Health Nursing, Faculty of Nursing, Menoufia University, Egypt \\ ${ }^{2}$ Maternal and Newborn Health Nursing, Faculty of Nursing, Cairo University, Egypt
}

Received: December 7, 2015

Accepted: March 23, 2016

Online Published: April 20, 2016

DOI: 10.5430/jnep.v6n9p18

URL: http://dx.doi.org/10.5430/jnep.v6n9p18

\begin{abstract}
Introduction: Breast engorgement is a painful condition that affects a huge number of postnatal women. It is associated with unsuccessful breastfeeding, mastitis, and breast inflammation. So, there is a need to increase awareness regarding the efficiency of different nursing interventions as: warm compresses and cold cabbage leaves to treat breast engorgement. The aim of the study was to reduce the level of breast engorgement among the postnatal mothers and to compare the effect of warm compresses versus cold cabbage leaves on breast engorgement.

Methods: A Quasi-experimental (equivalent pre-posttest group) research design was adopted. Setting: This study was conducted at postnatal ward and outpatient clinic at El-Manial Maternity hospital, Cairo Governate, Egypt. Subjects: A total of 90 postnatal mothers. They were randomly assigned into two groups (45 for each). Tools: Four tools were used to collect data; Maternal structured interviewing questionnaire, Six-points engorgement scale, Visual Analog Scale, and LATCH breastfeeding scale.

Results: The mean age of the mothers was $26.6 \pm 4.3$ years old. More than twenty percent of each group suffered from firm and tender breasts $(22.2 \% \& 28.9 \%)$. Also, there was a statistically significant difference between the pre and post symptoms of breast engorgement, levels of breast engorgement, pain score, and engorgement score for both groups $\left(p<.05^{*}\right)$. Hence, both the interventions were effective in relieving pain and reducing breast engorgement.

Conclusion: An application of cold cabbage leaves and warm compresses are effective for relieving breast engorgement. In addition, there was a statistically significant difference between the pretest and posttest of pain score and engorgement score for both groups $(p<.001 *)$. Recommendation: Nurses should be trained to include cold cabbage and warm compresses nursing approaches for managing breast engorgement in their discharge teaching plan. Also, prevention and early detection of breast engorgement should be done for all postnatal women.
\end{abstract}

Key Words: Nursing care, Breast engorgement, Postnatal women

\section{INTRODUCTION}

Breast engorgement is a painful congestion of the breasts with milk that can make it difficult for the baby to latch on to the mother breast properly. ${ }^{[1]}$ It characterized by the painful swelling of the breasts associated with the sudden increase in milk volume, vascular congestion, and edema during the first two weeks after birth. ${ }^{[1,2]}$ It may lead to a decreased milk supply, mastitis, and inflammation of the breast. It

\footnotetext{
*Correspondence: Reda Mohamed-Nabil Aboushady; Email: redaaboushady.77@gmail.com; Address: Maternal and Newborn Health Nursing, Faculty of Nursing, Cairo University, Egypt.
} 
caused by the buildup of breast milk during breastfeeding. ${ }^{[1]}$ The precipitating factors of breast engorgement include the poor latch, unsuccessful breastfeeds, decrease the duration of breastfeeding, missing baby early feeding cues, giving formula supplements to the baby, using a breast pump without a clinical indication, and causing overflow. ${ }^{[2,3]}$ Breast encouragement can hinder the development of successful breastfeeding, lead to early breastfeeding cessation, and associated with serious illness as breast infection. ${ }^{[4]}$ During lactation, breast engorgement can cause pain and inadequate milk emptying. ${ }^{[5]}$

Worldwide, the incidence rate of breast engorgement is 1:8000 and in India it is 1:6500 women. It occurs between the third to fourth day of postpartum and more than two-thirds of women develop tenderness on the fifth day of postpartum but some develop as late as nine to ten days postpartum. Approximately, two-thirds of women experience at least moderate symptoms of breast engorgement. ${ }^{[6]}$ Breastfeeding of a healthy infant occasionally turns into some challenges for the mother and her infant. Some of this challenges are predictable and another not predictable. ${ }^{[7,8]}$ They can hinder with the lactation process and worsen the maternal anxieties and worries. ${ }^{[9,10]}$ They may appear immediately after delivery or anytime during lactation. Several studies regarding breast engorgement have reported that the incidence rate of 2\%-3\% for mastitis, and 25\%-85\% for breast engorgement with plugged ducts. ${ }^{[10,11]}$ Breast engorgement is responsible for puerperal fever in thirteen percent of non-breastfeeding mothers. Observational studies conducted in the USA, Finland, New Zealand and Australia stated that up to twenty-five percent of breastfeeding women developed engorgement during the course of lactation and about thirty-five percent of them had recurrent episodes of engorgement. ${ }^{[6]}$

Generally, the woman with breast engorgement may find that her breasts become larger and heavy, warmer and uncomfortable when milk 'comes in', usually from two to six days after the baby is born. ${ }^{[12]}$ The first signs of the condition are the swollen, firm and painful breasts. In more severe cases, the affected breast becomes very swollen, hard, shiny, and slightly lumpy when touched. In cases when the breast is greatly engorged, the nipple is likely to retract into the areola. Ordinarily, women experience loss of appetite, fatigue, weakness, and chills. A fever may occur in fifteen percent of the mothers, but is typically less than $39^{\circ} \mathrm{C}$ and lasts for less than one day. ${ }^{[13]}$

Several approaches for the treatment of breast engorgement for breastfeeding women as: warm compresses before breastfeeding, cold therapy, cold cabbage leaves, breast massage, milk expression, and anti-inflammatory oral medi- cations. ${ }^{[13-15]}$ Also, Gua-Sha therapy may be used as an effective technique in the management of breast engorgement. By using Gua-Sha therapy, nurses can handle breast engorgement problems more effectively in primary care and help mothers both physically and psychologically. ${ }^{[16]}$ A warm shower can improve let-down and may make it easier to get milk out. ${ }^{[17]}$ Added to that, cabbage leave application is a very effective intervention in reducing breast engorgement for postnatal mothers. The need of the hour is to train and educate the social health workers, trained dais, and community health nurses regarding the significance of using the conventional, suitable, and economical methods of nursing care in reducing breast engorgement among postnatal mothers. ${ }^{[18]}$ Green cabbage leaves may be used chilled or at room temperature. The mother should wash cabbage leaves and apply to breasts between feedings. The nurse educates the mother to leave on for twenty minutes, no more than three times per day; stop use as soon as engorgement begins to subside because it can decrease milk supply. ${ }^{[19]}$

Based on the scientific evidence that cabbage leaves can reduce the pain of engorgement without side effects, and that use of cabbage leaves increases breastfeeding duration, beginnings will recommend the use of cabbage leaves for engorgement. ${ }^{[1]}$ So, lactation specialists and midwives recommend cabbage leaves to relieve the pain of engorgement. In addition, the nurse should advice mothers to avoid squeezing out milk since this tends to increase milk supply and cause engorgement to continue. ${ }^{[20]}$ Lactation consultants frequently recommend compresses made from green cabbage leaves to reduce swelling in moderate to severe engorgement. Cabbage is known to contain sinigrin rapine, mustard oil, magnesium, oxylate and sulphurheterosides. Cabbage has both antibiotic and anti-irritant properties. ${ }^{[1]}$

The nurses contribute to the health and well-being of women, children, and family, promoting skilled and specialized care in the clinical management of breastfeeding in their professional practice. Also, they should guide and demonstrate maneuvers to express milk to mothers so they can be performed when feeding their babies, and prevent the occurrence of breast engorgement. ${ }^{[21]}$ Counseling as a practice and technique is vital and significant relevance in allowing the health professionals to have the opportunity of carrying out not only educational but also assistance actions in the common illnesses at the beginning of breastfeeding. ${ }^{[22]} \mathrm{Car}-$ ing for breasts and nipples while breastfeeding includes wash breasts with water, not soap, allow nipples to air dry, wear breast-feeding pads, and change the breastfeeding position frequently. ${ }^{[23]}$

The nurse should focus on prevention of breast engorgement 
by providing counseling to the mother about starting breastfeeding as soon as possible after the birth, to give the baby time to learn to breastfeed before the breasts become full and firm, avoid early use of bottles, once the milk comes in, breastfeed at least eight times in 24 hours to prevent over fullness and use hand expression or a breast pump to remove the remaining milk. ${ }^{[24]}$ Also, early postpartum care is necessary to diagnose and treat complications. Studies have shown that mother's awareness regarding breast engorgement, symptoms, factors contributing to breast engorgement, prevention and management is low. ${ }^{[23]}$ So, the mother should be advised about gentle breast massage before breastfeeding, put on cool cloths to the breasts up to twenty minutes before offering the baby the breast, if the breast still uncomfortable after a feed, enough breast milk may be expressed to achieve comfort, and finally, ibuprofen may be useful to relieve discomfort. ${ }^{[12]}$ Also, a well fitted, supportive nursing bra makes some women feel better. ${ }^{[24]}$

\subsection{Significance of the study}

Breast engorgement is one of the most common breast implications occur in third and fourth postpartum day. It prevents the baby from keeping the nipple and areola in his or her mouth preventing effective breast milk flow. This leads to severe breast engorgement, which can cause great discomfort. Insufficient breast milk intake will subsequently occur and hinder normal infant growth. ${ }^{[16]}$ Lactation consultants frequently recommend compresses made from green cabbage leaves to reduce swelling in moderate to severe engorgement. ${ }^{[1]}$ It is theorized, that this natural mixture of components helps to decrease tissues congestion, allowing the body to reabsorb the fluid trapped in the breasts. Cabbage has a type of wicking action that helps move trapped fluid. ${ }^{[25]}$ Also, the application of warm compresses as an approach of nursing care on the engorge breasts promotes vasodilatation, increases circulation and, increase the volume of milk in the breasts. ${ }^{[26]}$ Midwives and community health nurses can play an important role in early detection and proper management of breast engorgement to maintain women health and enhance successful breastfeeding. A study on the efficacy of cabbage leaves can contribute to provide evidence for introducing this intervention in clinical practice; therefore, the present study contributes to a greater understanding to study the effect of warm compresses versus cold cabbage leaves as a two different approaches of nursing care to reduce the breast engorgement.

\subsection{Aim of the study}

The aim of the current has two folds:

(1) To reduce the level of breast engorgement among the postnatal mothers.
(2) To compare the effect of warm compresses versus cold cabbage leaves on breast engorgement.

\subsection{Research hypothesis}

(1) There will be a significant difference in the pre and post-test levels of breast engorgement among both groups.

(2) The mean post pain score will be less than the mean pre pain score for both groups.

\subsection{Definitions of terms}

Two different nursing care approaches in the present study refer to warm compresses versus cold cabbage leaves on the reduction of breast engorgement.

Warm compresses: Refers to the application of warm sponge cloth over the breasts. The temperature of the water for warm compresses ranged between $43^{\circ} \mathrm{C}$ to $46^{\circ} \mathrm{C}$ were replaced frequently after 1-2 minutes continued for the duration of 15-20 minutes.

Cold Cabbage leaves: Refers to apply cabbage leaves refrigerated in the freezer for approximately 20-30 minutes prior to the procedure. Cold cabbage leaves were placed inside the women brassiere for 15-20 minutes.

\section{SUBJECTS AND METHODS}

\subsection{Research design}

A Quasi-experimental (equivalent pre-posttest group) research design was adopted in this research. The most frequently used quasi-experimental design is the equivalent pretest-posttest design, which involves an experimental treatment and two groups of subjects observed before and after its implementation. ${ }^{[27]}$

\subsection{Setting}

The study carried out at postnatal ward and outpatient clinic at El-Manial Maternity hospital, Cairo Governorate, Egypt.

\subsection{Sample}

A Purposive sample of 90 postnatal women who delivered two days ago and were recruited after their acceptance to participate in the study. They were randomly assigned into two groups (45 for each). The first 45 subjects became the warm compresses group, and then the next 45 subjects were included in the cold cabbage leaves. This was done to avoid sample contamination and bias. The postnatal women were enrolled based on the inclusion and exclusion criteria. Informed consent was then obtained from them. Inclusion criteria: Postnatal mothers within 5 days of a post-natal period with the complaints of breast engorgement and willingness to participate in the study. Exclusion criteria: Mothers with 
an allergy to sulfa drugs, mothers receiving lactation suppressants, mothers with infection in the breasts, breast abscess, mastitis, a broken skin of breasts, or cracked nipples.

The sample size has been determined based on rule of the sum and sample equation based on information from relevant studies and the daily numbers of admission into postnatal unit throughout the period of data collection.

\subsection{Tools for data collection}

Four tools developed and filled by the researchers to collect data:

Maternal structured interviewing questionnaire: This tool was developed and used by the researcher after extensive literature review and it includes two parts: the first part contained questions related to 1) socio-demographic characteristics; 2) medical history; and 3) past and present obstetric history. As well the second part contained data related to signs and symptoms of breast engorgement.

Six-points engorgement scale: It was developed by Hill \& Humenick. ${ }^{[28]}$ It was used to assess the degree of breast engorgement which given the scoring ranges from 1 to 6 . Postnatal women response to the following questions, score as (1) for Soft and no changes in breast, score as (2) for slight changes in the breast, score as (3) for firm and no tender breast, score as (4) for firm, and beginning tenderness in breast, score as (5) for firm and tender of the breast, and score as (6) for very firm and very tender.

Visual analog scale (VAS): It was adopted from Gift. ${ }^{[29]}$ It was used to assess the degree of pain intensity and consisted of a blank line anchored at each end of the line by adjectives that describe the extremes of pain. For ease of measurement a $10 \mathrm{~cm}$ line usually is used. The anchoring adjectives commonly used are "no pain" and "severe pain" (worst possible pain). The postnatal women are asked to place a mark on the line that best indicates the pain being experienced. Measuring from the end of the line to mark made by the postnatal women gives a numeric rating of the intensity of the pain. Scoring: the score zero (0) indicates no pain and the top score (10) indicates the worst possible pain. The VAS was divided into 3 main parts: the first part graded from $1-3 \mathrm{~cm}$ which reflects mild pain, the second part graded from $4-7 \mathrm{~cm}$ for moderate pain and the third part graded from $8-10 \mathrm{~cm}$ for severe pain.

LATCH breastfeeding charting scale: It was developed by Jensen et al. ${ }^{[30]}$ based on the model of the Apgar scoring system. The system assigns a numerical score $(0,1$, or 2$)$ to five key breastfeeding components identified by the letters of the acronym LATCH: "L" for how well the infant latches onto the breast, "A" for the amount of audible swallowing noted, "T" for the mother's nipple type/condition, "C" for the mother's level of comfort, and " $\mathrm{H}$ " for the amount of help the mother needs to hold her infant to the breast. The total score ranged from 0 to 10 , with the higher score representing successful breastfeeding.

\subsection{Reliability and validity of the tool}

The tools designed by the researcher and revised by experts in the field of community and maternity health nursing to content validity. Regarding maternal structured interviewing questionnaire, modifications were carried out according to the panel judgment on clarity of the sentences and appropriateness of the content. Reliability test was assessed by applying the questionnaire on 10 postnatal women using test-retest.

\subsection{Pilot study}

A total of $10 \%$ of the sample were included in the pilot study recruited from postnatal ward and outpatient clinic in order to assess the feasibility and clarity of the tools and determine the needed time to answer the questions. The postnatal women informed about the aim of the study before the intervention. Pilot study revealed that, the average length of time needed to complete the maternal structured interview schedule; it was approximately 30 minutes with each postnatal woman. Based on its result changes were carried out. Sample included in the pilot study were excluded from the study sample.

\subsection{Procedure}

A written permission from the institutional authority of maternity hospital was obtained before conducting the study. After that, acceptance of the women who were participated in the study. The researcher was introduced herself to postnatal women who met the inclusion criteria and inform them about the purpose of this research in order to be obtain their written acceptance to recruited in this research as well as to gain their cooperation. The researcher was constructed and prepared of the different data collection tools, designed the nursing care approaches, teaching materials of booklets was developed by the researcher and revised by experts in the field of maternity and community health nursing in addition to seeking managerial arrangement to carry out the study.

Data collection was carried out through three phases: interviewing and assessment phase, implementation phase, and evaluation phase.

Interviewing and assessment phase: In this phase, data collected over a period of 7 months from beginning of May 2015 to end of November 2015 in the postnatal ward and out patient's clinic from 9 AM to 2 PM, three days per week. 
The postnatal women were enrolled based on the inclusion and exclusion criteria, the identification data and obstetric characteristics of each subject were recorded in a validated subject data sheet. This interview and assessment phase consumed about 30 minutes for each woman; the postnatal women were asked in Arabic language and documented her answer in the tools utilized.

Implementation phase: In this phase, the selected parturient were randomly assigned into two groups (45 for each). The first group comprised of 45 postnatal who were encouraged to administer warm compresses treatment for reducing breast engorgement. Alternate warm moist sponge cloths and warm shower were applied to the engorged breasts; the cloths were replaced frequently after 1-2 minutes continued for the duration of 15-20 minutes. The temperature of the water for warm compresses ranged between $43^{\circ} \mathrm{C}$ to $46^{\circ} \mathrm{C}$ and for the warm shower as assessed by a lotion thermometer were replaced frequently after 1-2 minutes continued for the duration of 15-20 minutes.

After the completion of this group, the next group comprised of 45 postnatal women who were encouraged to administer cold cabbage leaves treatment for reducing breast engorgement. Cabbage leaves rinsed carefully before use. A patch test was done by applying a small piece of cabbage leaf on the skin to test sensitivity before starting the treatment. Cabbage leaves were refrigerated in the freezer for approximately 20-30 minutes before application. Apply the cabbage leaves directly to breasts, wearing them inside of the bra. Cold cabbage leaves were placed inside the women bra for 15-20 minutes. Remove wilted leaves and reapplies fresh leaves. Scientific evidenced mentioned that, cold green cabbage (Brassica capitata) is used for engorgement therapy. In addition, Cabbage is known to contain sinigrin rapine, mustard oil, magnesium, oxylate and sulphurheterosides. And has both antibiotic and anti-irritant properties. ${ }^{[31]}$

To assess the pain and engorgement score for both groups, they were assessed before and after the two different methods of nursing care. The duration of each intervention was 15-20 minutes. If the baby is unable to feed frequently enough, then fully drain the breasts once or twice daily with an effective breast pump until engorgement is disappeared.

Evaluation phase: In this phase, all postnatal women recruited in the study were evaluated for the levels of breast engorgement, symptoms, pain, and the LATCH. Breast engorgement was measured using a six-point breast engorgement scale, and the pain score was assessed using the VAS. This posttest consumed about 15-20 min for each woman. Also continuous a telephone contact between the researcher and women to determine exact time for measuring posttest at outpatient clinic. The all postnatal women permitted to ask questions for clarify any statement that she did not understand. The researcher also recorded any complaints or needs, and offered referral to outpatient clinics.

\subsection{Ethical considerations}

An official permission was taken from the authoritative personal in the maternity hospital. The researchers introduced themselves to postnatal women who met the inclusion criteria and informed them about the aim of the current study in order to obtain their acceptance to share in this study. Written consent was obtained from postnatal women who were willing to participate in the study. Confidentiality and anonymity of them were assured through coding the data.

\subsection{Statistical analysis}

The collected data were scored, tabulated and analyzed using Statistical Package for the Social Science (SPSS) program version 20. Descriptive as well as parametric inferential statistics were utilized to analyze data pertinent to the study. The level of significance was set at $p<.05$. Paired sample $t$-test and independent sample $t$-test were used to analyze the data.

Table 1. Percentage Distribution of Socio-demographic Characteristics and Health Related Data among Studied Sample $(n=90)$

\begin{tabular}{llll}
\hline $\begin{array}{l}\text { Socio-demographic } \\
\text { Characteristics and } \\
\text { Health Related Data }\end{array}$ & $\begin{array}{l}\text { Cold Cabbage } \\
\text { leaves (n=45) }\end{array}$ & $\begin{array}{l}\text { Warm comp- } \\
\text { resses (n=45) }\end{array}$ & Total \\
\hline $\begin{array}{l}\text { Age (years old) } \\
\text { Residence }\end{array}$ & $26.3 \pm 4.04^{\#}$ & $27.0 \pm 4.6^{\#}$ & $\underline{26.6 \pm 4.3^{\#}}$ \\
$\begin{array}{l}\text { Rural } \\
\text { Urban }\end{array}$ & $48.9 \%$ & $48.9 \%$ & $48.9 \%$ \\
$\begin{array}{l}\text { Education } \\
\text { illiterate }\end{array}$ & $51.1 \%$ & $51.1 \%$ & $\underline{51.1 \%}$ \\
read \& write & $6.7 \%$ & $11.1 \%$ & $8.9 \%$ \\
primary education & $22.2 \%$ & $26.7 \%$ & $24.4 \%$ \\
high education & $28.9 \%$ & $35.6 \%$ & $32.2 \%$ \\
$\begin{array}{l}\text { Occupation } \\
\text { Working }\end{array}$ & $42.2 \%$ & $26.7 \%$ & $\underline{34.4 \%}$ \\
House wives & $51.1 \%$ & & \\
Monthly income & $1,648.8 \pm 0.52$ & $1,451.1 \pm 0.38$ & $1,550.0 \pm 0.46$ \\
\hline
\end{tabular}

$\#=$ mean $\pm \mathrm{SD}$

\section{Results}

The study sample included 90 postnatal women with the mean age of the sample was $26.6 \pm 4.3$ years old. More than half of the sample $(51.1 \%)$ was from urban areas and $34.4 \%$ of them were highly educated. Also, more than fifty percent of the participants were housewives (52.2\%) (see Table 1).

Table 2 reveals that more than half $(62.2 \%, 68.9 \%)$ of the studied sample were delivered normally, and the remaining 
of them had a cesarean section within 3 to 4 days postpartum with the mean $(3.8 \pm 0.7)$. More than half of the participants breastfed their baby along 10 minutes and 20 minutes for more than twenty-five percent of them. Added to that, the preferred maternal position for breastfeeding was sitting position $(60.0 \%, 64.4 \%)$ with one hour of frequency for feeding $(53.3 \%, 66.7 \%)$. Also, there was no statistically significant difference between the two groups regarding maternal and neonatal characteristics.

Table 2. Distribution of Maternal and Neonatal Characteristics for the Sample

\begin{tabular}{|c|c|c|c|}
\hline $\begin{array}{l}\text { Maternal and } \\
\text { Neonatal } \\
\text { Characteristics }\end{array}$ & $\begin{array}{l}\text { Cold Cabbage } \\
\text { leaves }(n=45)\end{array}$ & $\begin{array}{l}\text { Warm comp- } \\
\text { resses }(n=45)\end{array}$ & $p$ \\
\hline Parity & $1.51 \pm 0.6^{\#}$ & $1.8 \pm 0.9^{\#}$ & \multirow{3}{*}{$p>.05$} \\
\hline Primi & 62.2 & 62.2 & \\
\hline Multi & 37.8 & 37.8 & \\
\hline $\begin{array}{l}\text { Type of delivery } \\
\text { Normal } \\
\text { CS }\end{array}$ & $\frac{62.2 \%}{37.8 \%}$ & $\frac{68.9 \%}{31.1 \%}$ & $p>.05$ \\
\hline $\begin{array}{l}\text { Number of } \\
\text { postpartum days } \\
1-3 \\
3-5\end{array}$ & $\begin{array}{l}\frac{3.8 \pm 0.7^{\#}}{35.6 \%} \\
64.4 \%\end{array}$ & $\begin{array}{l}\frac{3.7 \pm 0.7^{\#}}{40.0 \%} \\
60.0 \%\end{array}$ & $p>.05$ \\
\hline $\begin{array}{l}\text { Duration of breast } \\
\text { feeding } \\
10 \text { minutes } \\
20 \text { minutes } \\
30 \text { minutes }\end{array}$ & $\begin{array}{l}42.2 \% \\
26.7 \% \\
31.1 \%\end{array}$ & $\begin{array}{l}\frac{53.3 \%}{26.7 \%} \\
20.0 \%\end{array}$ & $p>.05$ \\
\hline $\begin{array}{l}\text { Maternal Position } \\
\text { for feeding } \\
\text { Sitting } \\
\text { Side lying }\end{array}$ & $\frac{60.0 \%}{40.0 \%}$ & $\frac{64.4 \%}{35.6 \%}$ & $p>.05$ \\
\hline $\begin{array}{l}\text { Frequency of } \\
\text { feeding (in hours) } \\
1 \text { hour } \\
2 \text { hours } \\
3 \text { hours }\end{array}$ & $\begin{array}{l}\frac{53.3 \%}{35.6 \%} \\
11.1 \%\end{array}$ & $\begin{array}{l}\frac{66.7 \%}{17.8 \%} \\
15.6 \%\end{array}$ & $p>.05$ \\
\hline Baby weight by gm & $2,950 \pm 0.45 \mathrm{gm}^{\#}$ & $2,951 \cdot 1 \pm 0.40 \mathrm{gm}^{\#}$ & $p>.05$ \\
\hline Total & $45(100.0 \%)$ & $45(100.0 \%)$ & \\
\hline
\end{tabular}

Concerning symptoms and levels of engorgement, table 3 clarifies that more than twenty percent of each group were suffered from firm and tender breasts $(22.2 \%, 28.9 \%)$ with level 4 of engorgement. Also, there was a statistically significant difference between the pre and post symptoms and levels of breast engorgement for the two groups $\left(p<.05^{*}\right)$. The two methods (cold cabbage leaves and warm compresses) for the management of breast engorgement were effective. In addition, the pain score for the cold cabbage group reduced from $7.76 \pm 1.3$ during the pretest to become $2.28 \pm 0.8$ during the posttest. While the group who use warm compresses, their pain score reduced from $8.1 \pm 1.15$ to become $4.3 \pm$ 0.7 during the posttest.

Published by Sciedu Press
Table 3. Distribution of Symptoms and Levels of Breast Engorgement $(\mathrm{n}=90)$

\begin{tabular}{|c|c|c|c|c|c|}
\hline \multirow{2}{*}{$\begin{array}{l}\text { Symptoms and } \\
\text { Levels of Breast } \\
\text { Engorgement }\end{array}$} & \multicolumn{2}{|c|}{$\begin{array}{l}\text { Cold Cabbage leaves } \\
(\mathrm{n}=45) \text { (paired } t \text { test) }\end{array}$} & \multicolumn{2}{|c|}{$\begin{array}{l}\text { Warm compresses } \\
(n=45)\end{array}$} & \multirow[t]{2}{*}{$p$ value } \\
\hline & pre & post & pre & post & \\
\hline \multicolumn{6}{|l|}{ Pain } \\
\hline $\begin{array}{l}\text { The pain radiated to } \\
\text { axilla }\end{array}$ & $86.7 \%$ & $13.3 \%$ & $91.1 \%$ & $42.2 \%$ & \multirow{2}{*}{$\begin{array}{l}\text { (Independent } \\
t \text {-test) }\end{array}$} \\
\hline \multirow[t]{2}{*}{ Pain Score } & $\begin{array}{l}59.0 \% \\
7.76 \pm 1.3^{\#}\end{array}$ & $\begin{array}{l}0.0 \% \\
2.28 \pm 0.8^{\#}\end{array}$ & $\begin{array}{l}63.4 \% \\
8.1 \pm 1.15^{\#}\end{array}$ & $\begin{array}{l}7.3 \% \\
4.3 \pm 0.7^{\#}\end{array}$ & \\
\hline & $t=24.1$ & $p<.001^{*}$ & $t=19.9$ & $p<.001^{*}$ & $t=10 \quad p<.001^{*}$ \\
\hline \multicolumn{6}{|l|}{$\begin{array}{l}\text { Levels of } \\
\text { engorgement }\end{array}$} \\
\hline $\begin{array}{l}1 \rightarrow \text { Soft, no changes } \\
\text { in breast. }\end{array}$ & $8.9 \%$ & $71.1 \%$ & $13.3 \%$ & $71.1 \%$ & \multirow{21}{*}{$t=1.06, p>.05$} \\
\hline $\begin{array}{l}2 \rightarrow \text { Slight changes in } \\
\text { the breast. }\end{array}$ & $24.4 \%$ & $28.9 \%$ & $17.8 \%$ & $20.0 \%$ & \\
\hline $3 \rightarrow$ Firm, no tender & $15.6 \%$ & $0.0 \%$ & $13.3 \%$ & $4.4 \%$ & \\
\hline breast. & & & & & \\
\hline $\begin{array}{l}4 \rightarrow \text { Firm, beginning } \\
\text { tenderness in breast. }\end{array}$ & $22.2 \%$ & $0.0 \%$ & $28.9 \%$ & $2.2 \%$ & \\
\hline $5 \rightarrow$ Firm, tender. & $17.8 \%$ & $0.0 \%$ & $15.6 \%$ & $2.2 \%$ & \\
\hline $6 \rightarrow$ Very firm, very & $11.1 \%$ & $0.0 \%$ & $11.1 \%$ & $0.0 \%$ & \\
\hline tender. & $7.76 \pm 1.3^{\#}$ & $1.2 \pm 0.4^{\#}$ & $3.4 \pm 1.56^{\#}$ & $1.4 \pm 0.8^{\#}$ & \\
\hline \multirow[t]{2}{*}{ Fever } & $35.6 \%$ & $0.0 \%$ & $37.8 \%$ & $2.2 \%$ & \\
\hline & $p<.05^{*}$ & & $p<.05^{*}$ & & \\
\hline \multirow[t]{2}{*}{ Swelling } & $17.8 \%$ & $0.0 \%$ & $13.3 \%$ & $0.0 \%$ & \\
\hline & $p<.05$ & & $p<.05$ & & \\
\hline \multirow[t]{2}{*}{ Redness } & $66.7 \%$ & $0.0 \%$ & $73.3 \%$ & $0.0 \%$ & \\
\hline & $p<.05^{*}$ & & $p<.001 *$ & & \\
\hline \multirow[t]{2}{*}{ Warmness } & $55.6 \%$ & $4.4 \%$ & $64.4 \%$ & $15.6 \%$ & \\
\hline & $p<.001^{*}$ & & $p<.001 *$ & & \\
\hline \multirow[t]{2}{*}{ Fatigue } & $60.0 \%$ & $20.0 \%$ & $80.0 \%$ & $26.7 \%$ & \\
\hline & $p<.001 *$ & & $p<.05^{*}$ & & \\
\hline \multirow[t]{2}{*}{ Headache } & $51.1 \%$ & $0.0 \%$ & $40.0 \%$ & $6.7 \%$ & \\
\hline & $p<.001^{*}$ & & $p<.001 *$ & & \\
\hline Total & 45 & $100.0 \%$ & 45 & $100.0 \%$ & \\
\hline
\end{tabular}

Figure 1 explains that the most frequent symptoms of breast engorgement that occurred to the studied women were breast pain $(88.9 \%)$, redness of the breast $(70.0 \%)$, fatigue $(70.0 \%)$, and warmness of the breast during touch $(60.0 \%)$, headache $(45.6 \%)$, and fever $(36.7 \%)$.

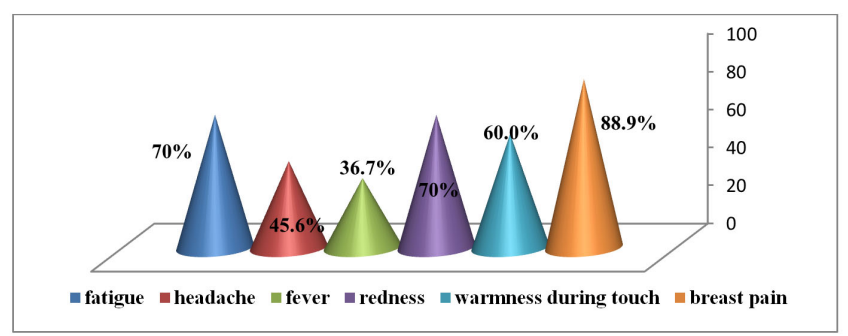

Figure 1. Symptoms of Breast Engorgement among Studied Women

Figure 2 shows that the most reported causes of breast engorgement during the present study were history of breast engorgement $(65.6 \%)$, primipara $(62.2 \%)$, did not breastfeed all milk to the baby $(61.1 \%)$, obesity $(53.3 \%)$, inability of the baby to catch the nipple appropriately $(51.1 \%)$, and limited duration of breastfeeding only along 10 minutes or less $(47.8 \%)$. 


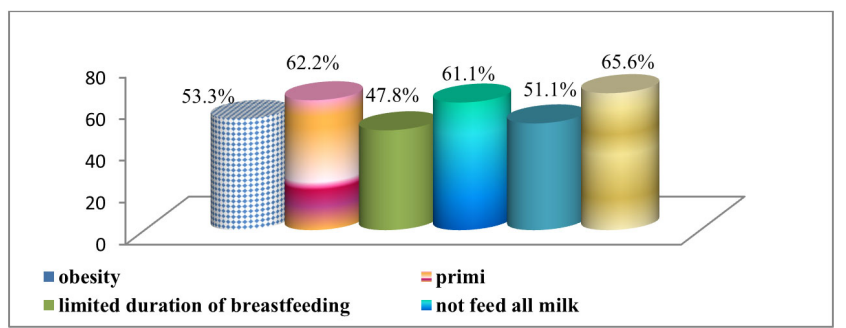

Figure 2. The Common Reported Causes of Breast Engorgement

It was observed that there is a statistically significant difference between the pretest and posttest of the pain score and engorgement score for the cold cabbage group and the warm compresses group $(p<.001 *)$. The engorgement score reduced from $3.4 \pm 1.53$ to $1.2 \pm 0.4$ after the intervention (see Table 4). Also, the table reveals that there was a significant improvement of breastfeeding assessment and intervention for the mothers and her babies due to the reduction of breast engorgement after application of the two different nursing approaches (cold cabbage leaves versus warm compresses) $\left(p<.05^{*}\right)$.

Table 4. Comparison of Changes in Mean Pain, Engorgement and LATCH Score Before and After the Intervention among studied groups

\begin{tabular}{|c|c|c|c|}
\hline $\begin{array}{l}\text { Pain and } \\
\text { Engorgement Score }\end{array}$ & $\begin{array}{l}\text { Pre- } \\
\text { intervention }\end{array}$ & $\begin{array}{l}\text { Post- } \\
\text { intervention }\end{array}$ & $\begin{array}{l}t-p \text {-value } \\
\text { (paired- } t \text { test) }\end{array}$ \\
\hline \multicolumn{4}{|l|}{ Pain score } \\
\hline $\begin{array}{l}\text { - Cold cabbage leaves } \\
(\mathrm{n}=45)\end{array}$ & $7.76 \pm 1.3^{\#}$ & $2.28 \pm 0.8^{\#}$ & $t=24.1 p<.001^{*}$ \\
\hline $\begin{array}{l}\text {-Warm compresses } \\
(\mathrm{n}=45)\end{array}$ & $8.1 \pm 1.15^{\#}$ & $4.3 \pm 0.7^{\#}$ & $t=19.9 p<.001^{*}$ \\
\hline \multicolumn{4}{|l|}{ Breast engorgement } \\
\hline $\begin{array}{l}\text {-Cold cabbage leaves } \\
(n=45)\end{array}$ & $3.4 \pm 1.53^{\#}$ & $1.2 \pm 0.4^{\#}$ & $t=8.9 p<.001^{*}$ \\
\hline $\begin{array}{l}\text {-Warm compresses } \\
(n=45)\end{array}$ & $3.4 \pm 1.56^{\#}$ & $1.4 \pm 0.8^{\#}$ & $t=7.8 p<.001^{*}$ \\
\hline \multicolumn{4}{|l|}{ LATCH score } \\
\hline $\begin{array}{l}\text {-Cold cabbage leaves } \\
(n=45)\end{array}$ & $5.1 \pm 1.04^{\#}$ & $6.2 \pm 1.6^{\#}$ & $t=3.8 p<.0001^{*}$ \\
\hline $\begin{array}{l}\text {-Warm compresses } \\
(\mathrm{n}=45)\end{array}$ & $5.02 \pm 1.2^{\#}$ & $6.1 \pm 1.7^{\#}$ & $t=4.5 p<.0001^{*}$ \\
\hline
\end{tabular}

${ }^{*}=$ mean $\pm \mathrm{SD}$; * significant difference

\section{Discussion}

Breast engorgement is a common problem among postnatal women worldwide. It is influenced the confidence and continuation of breastfeeding in the first week following birth. ${ }^{[31,32]}$ In addition, improper infant sucking, position, abrasion of the nipple and mastitis can occur. ${ }^{[1,33]}$ Cold cabbage leaf used for women with breast engorgement to reduce pain, the firmness of the engorged breasts, and increased the duration of breastfeeding. ${ }^{[34]}$ Also, the use of warm compresses on the engorged breasts can promote vasodilatation, and increases circulation, and volume of milk in the breasts. ${ }^{[26]}$ Therefore, the current study aimed to reduce the level of breast engorgement among the postnatal mothers and to compare the effect of warm compresses versus cold cabbage leaves on breast engorgement.

The present study shows that the mean age of the sample was $26.6 \pm 4.3$ years old and thirty-four percent of them were highly educated. This comes in agreement with a study performed by Eapen $\&$ Fernandes, ${ }^{[35]}$ regarding the effectiveness of an information booklet on measures for managing breast engorgement. They reported that the highest percentage of mothers were in the age group of twenty-four to twenty-nine years old, twenty-seven percent in the age group of 18-23 years, twenty percent were between $30-35$ years and five percent were above thirty-five years of age. The educational status reveals that the majority of them completed high education, and thirty percent completed primary school.

Mothers who have cesarean delivery are very vulnerable to the hardships that come along three to four days after birth including sore and swollen breasts. Giving anticipatory assistance to succeed with breastfeeding amongst these possible concerns and challenges are important to help mothers gain the confidence to succeed in making breastfeeding. ${ }^{[36]}$ The present study stated that more than thirty percent of the studied women had a cesarean section within three to four days postpartum and more than sixty percent of them were delivered normally. Of course, the immediate postpartum period is difficult for mothers who delivered by cesarean section because of pain which can effect on the mother ability to breastfed her baby early and can contribute to breast engorgement. Also, the present study stated that more than half of the mothers breastfed their babies along ten minutes and twenty minutes for more than twenty-five percent of them with one hour of frequency for feeding. This comes on the same line with Gauss, ${ }^{[37]}$ who stated that the mother should follow the baby's cues for feeding on demand. When the baby begins to elicit a feeding cue, place him/her on the breast. Feeding early and feeding often will help to make sure good milk transfer is occurring. Also, Motee et al., ${ }^{[38]}$ added that proper breastfeeding practices are effective ways for reducing childhood morbidity and mortality. While many mothers understand the importance of breastfeeding, others are less knowledgeable about the benefits of breastfeeding. Reasons found to influence infant feeding practices are the type of delivery, parity, occupation, education, and breast problems. Added to that, the present study stated that, the preferred maternal position for breast feeding was sitting position with one hour of frequency for feeding. Another study focused on the evaluation of the knowledge, attitude 
and practices of breastfeeding among Nigerian mothers from a semi-urban community summarized that, sitting on a chair to breastfeed was the common technique for feeding the baby. Cross-cradle hold, football hold technique, breast-to-baby and baby-to-breast latch-on were the common breastfeeding techniques. A majority of the participants approved that neck flexion, slight back flexion, arm support with a pillow, and foot rest was essential during breastfeeding. [39]

Concerning symptoms and levels of breast engorgement, the current study illustrated that more than twenty percent of each group were suffered from firm and tender breasts (Level 4 of engorgement). Also, there was a statistically significant difference between the pre and post symptoms and levels of breast engorgement for the two groups $\left(p<.05^{*}\right)$. The two different methods of nursing care (cold cabbage leaves and warm compresses) for the management of breast engorgement were effective. In the same line of agreement, a study done to relate the usefulness of topical use of alternating cold and hot compresses to frozen cabbage leaves for the treatment of breast engorgement. They mentioned that each treatment was applied for 30 minutes 3 times daily for 2 days. Both treatments were effective in reducing pain and engorgement. On the other hand, the authors concluded that hot and cold compresses were more effective than cabbage leaves. ${ }^{[40]}$ In addition, the current study reported that, pain score for the cold cabbage group reduced from $7.76 \pm 1.3$ during the pretest to become $2.28 \pm 0.8$ during the posttest. While the group who use warm compresses, their pain score reduced from $8.1 \pm 1.15$ to become $4.3 \pm 0.7$ during the posttest.

As one of the most common causes of lactation failure, symptoms of engorgement involve swelling within the breast tissue. This is most common on the third postpartum day at the onset of large amounts of milk production. The breasts become firm, warm, painful and throbbing and the nipples become retracted. Temperature increases in some women. If severe engorgement occurs, the firmness of the areola may prevent the infant from latching. Early engorgement results from a combination of edema, tissue swelling and milk production whereas engorgement that occurs later is usually severely due to accumulated milk. ${ }^{[41]}$ Results of the current study illustrates that the most reported symptoms of breast engorgement that occurred among the studied sample included the following; breast pain, redness of the breast, fatigue, and warmness of the breast during touch, headache, and fever. This finding is in consistent with Gauss, ${ }^{[37]}$ who mentioned that breasts may feel swollen, fuller, and heavier. In some cases, women describe the breasts as being warm and appear hard and shiny. Women may notify some redness of the skin; get a slight fever and experience chills and

Published by Sciedu Press nausea for a few hours. These findings may be interrelated to increase breast milk volume as well as an increase blood and fluids flow in the breast ducts to assist the glands with making milk.

Breast engorgement can result from several causes. The reported causes during the current study included: history of breast engorgement, primipara, did not breastfeed all milk to the baby, obesity, inability of the baby to catch the nipple appropriately, and inadequate duration of breastfeeding. Breast engorgement reasons also include poor latch, not breastfeeding frequently enough to empty breasts, and limited breastfeeding schedule. ${ }^{[42]}$ According to Murray, ${ }^{[43]}$ added other causes as: not breastfeeding enough, supplement with formula between feedings, irregular baby's schedule of sleeping, over abundant milk supply, and baby illness. This is incongruent with the current study findings; also, the limited knowledge and experience of the mother about breastfeeding will contribute to other problems, so if the mother doesn't know how to put her baby in right position and the good attachment on the breast, mother will enter the field of all other critical problems like sore nipple, breast congestion, blocked milk duct, mastitis, and end in early introduction of bottle feeding and stopping the initiation and maintenance of breastfeeding. ${ }^{[44]}$ This may be related to the discharge plan not include these part of information. So, we are recommended that community nurses and midwives should be trained to include the different nursing care for managing breast engorgement in their teaching.

There are several approaches for the treatments of breast engorgement have been explored as; cold cabbage compresses. ${ }^{[45]}$ In Taiwan a Randomized Controlled Trial used massage therapy as a form of treatment. ${ }^{[16,46]}$ According to Wong $\&$ his colleges ${ }^{[34]}$ they stated that, cabbage leaf treatment used on women with breast engorgement to reduce pain, the firmness of the engorged breasts and increased the duration of breastfeeding. In the present study, table four shows that there was a statistically significant difference between the pretest and posttest of the pain score and engorgement score for the cold cabbage group and the warm compresses group $\left(p<.001^{*}\right)$. The engorgement score reduced from 3.4 \pm 1.53 to $1.2 \pm 0.4$ after the intervention. This finding is in consistent with Saini \& Saini, ${ }^{[18]}$ during an uncontrolled pilot study in 30 women with breast engorgement compared pain scores before and after the mothers applied refrigerated cabbage leaves to their breasts two times a day for three days for fifteen to twenty minutes. Engorgement scores were lower after three days than at the beginning of the study.

A study done by Najem \& Dhia Al-Deen, ${ }^{[44]}$ reported that lacking of prenatal education of primi mothers about breast- 
feeding merely eight percent of mothers received breastfeeding education reflects difficulties particularly in the early postnatal period which is a critical period in starting and continuation of breastfeeding. Among these difficulties, the mother did not have the experience to put the baby in the right position or latch on, refusal of the baby to breastfed and believing that she has inadequate milk. The current study revealed that there was a significant improvement of breastfeeding assessment and intervention for the mothers and her babies due to the reduction of breast engorgement after application of the two different nursing interventions (cold cabbage leaves versus warm compresses) $\left(p<.05^{*}\right)$. LATCH breastfeeding charting scale was developed by Jensen $e t$ al., ${ }^{[30]}$ based on the model of the Apgar scoring system. Its simplicity makes systematic documentation and communication easy. The system assigns a numerical score to five key breastfeeding components identified by the letters of the acronym LATCH. Usually, the treatment for breast engorgement should be based on maintaining breastfeeding and systematic manual milking of the breast to balance milk supply and infant demand. Frequent breastfeeding is highlighted, whenever the baby feels hungry, besides advising mothers regarding the correct latching and suction. Most difficulties that occur during lactation, when early treated, are easy to solve and result in satisfactory experiences for the woman and newborn, considering that breastfeeding is an important process after childbirth, with a positive relationship with the newborn's feeding and benefits for the woman's health. ${ }^{[47]}$ Women who have not received any breastfeeding assistance at all present thirty-four and thirty-six percent occurrence of breast engorgement from seven to thirty days after discharge, respectively. ${ }^{[48]}$

\section{Conclusion}

Based on the findings of the present study, an application of cold cabbage leaves and warm compresses are effective for relieving breast engorgement. In addition, there was a statistically significant difference between the pretest and posttest of the pain score and engorgement score for the cold cabbage group and the warm compresses group $(p<.001 *)$. Both the two approaches of nursing care were successfully implemented in the clinical setting. As both the treatment modalities are low cost and available. It can be implemented by the nurses in the day to day practice at the hospital as well as at home to reduce breast engorgement.

\section{RECOMMENDATIONS}

Based on the study findings the following recommendations are suggested:

(1) Early detection and nursing care are important to improve the infants' breastfeeding experience and prevent the breast complications.

(2) Nurses should be trained to include the cold cabbage and warm compresses nursing approaches for managing breast engorgement in their discharge teaching plan.

(3) Cold cabbage leaves compresses between feedings will reduce breast swelling and relieve pain.

(4) A warm shower or the application of warm compresses immediately before breastfeeding will encourage milk flow and reduce pain.

(5) Breastfeeding every 2 hours prevents congestion in the breasts.

(6) Support infant's nutrition and maternal milk supply through optimizing breastfeeding management.

(7) This area of research needs additional efforts in order to expand the evidence base on the different nursing care approaches on reduction of breast engorgement.

\section{ACKNOWLEDGEMENTS}

We would like to thank all postnatal women who agreed to participate in the study and helped us to shed light on how they handle breast engorgement as an important element during postpartum period.

\section{Conflicts of InTERest Disclosure}

The authors declare that there is no conflict of interest.

\section{REFERENCES}

[1] Lawrence RM, Lawrence RA. Given the benefits of breastfeeding, what contraindications. Pediatric Clinics of North America. 2005; 48(1): 235-251.

[2] Ministry of Health - Manat Hauora. Breast engorgement and breast oedema. Health Workforce New Zealand. 2015. Available from: http://www.health.govt.nz/our-work/life-stages/br eastfeeding/health-practitioners/breast-engorgeme nt-and-breast-oedema. Accessed at 23 October 2015.
[3] Williams. Breast feeding and Engorgement. Obstetrics. 24th ed. McGraw-Hill Professional. 2014. pp. Chapter 37. ISBN 9780071798938.

[4] Mangesi L, Dowswell T. Treatments for breast engorgement during lactation. Cochrane Database. Syst Rev. 2010 Sep; 8(9).

[5] Boskabadi H, Ramazanzadeh M, Zakerihamidi M, et al. Risk factors of breast Problems in mothers and its effects on newborns. Iranian Red Crescent Medical Journal. 2014; 16(6).

[6] Sangar K. Engorgement of breast-potential problem in lactation. 
Nightingale Nursing Times. 2004 Aug; 1(5): 17-21.

[7] Wambach K, Campbel SH, Gill SL, et al. Clinical lactation practice: 20 years of evidence. Journal of Human Lactation. 2005; 21(3): 245-258. PMid:16113013. http://dx.doi.org/10.1177/08903 34405279001

[8] Boskabadi H, Maamouri G, Ebrahimi M, et al. Neonatal hypernatremia and dehydration in infants receiving inadequate breastfeeding. Asia Pacific journal of clinical nutrition. 2010; 19(3): 301.

[9] Giugliani ER. Common problems during lactation and their management. Journal de pediatria. 2004; 80(5): s147-s154.

[10] Richard JS, Lisa E, Steven A, et al. Patient information Common breastfeeding problems Breastfeeding Problems Overview. 2010. Available from: http://www . uptodate.com/conten

[11] American Academy of Pediatrics, American College of Obstetricians and Gynecologists. Breastfeeding Handbook for Physicians. 2006. 1st ed. Washington DC: American Academy of Pediatrics.

[12] Australian Breastfeeding Association. Engorgement. 2014. Available from: https://www.breastfeeding.asn.au/bf-info/comm on-concerns $\%$ E $2 \% 80 \% 93$ mum/engorgement. Accessed at 9 October 2015.

[13] Chang YS, Chang ML. Introduction to Chinese medicine nursing. 2007. Taipei, Taiwan, ROC: Wenchin. (Original work published in Chinese).

[14] Hung CH. Postpartum care. In: T. Y. Lee (Ed.). Practical obstetric nursing. 2008. 5th ed., pp. 531Y542. Taipei, Taiwan, ROC: Farseeing. (Original work published in Chinese).

[15] Newman J, Kernerman E. Blocked ducts and mastitis. Retrieved March 8, 2009. Available from: http://nbci.ca/index.php?op tion=com_content\&view=article\&id=7: blocked-ducts-a -mastitis\&catid=5: information\&Itemid=17. Accessed at 25 October 2015

[16] Chiu JY, Gau ML, Kuo SY, et al. Effects of Gua-Sha therapy on breast engorgement: a randomized controlled trial. Journal of Nursing Research. 2010; 18(1): 1-10. PMid:20220605. http://dx.doi . org/10.1097/JNR. 0b013e3181ce4f8e

[17] Spence J. Patient information. Common breastfeeding problems. 2015. Available from: http://www. uptodate.com/contents/ common-breastfeeding-problems-beyond-the-basics. Accessed at 25 October 2015.

[18] Saini P, Saini R. Cabbage leaves and breast engorgement. Indian Journal of Public Health. 2014; 58(4): 291-292. PMid:25491528. http://dx.doi.org/10.4103/0019-557X.146309

[19] Bonyata K. Engorgement. 2015. Available from: http://kellym om. com/bf/concerns/mother/engorgement/. Accessed at 25 October 2015.

[20] Smith S. Cabbage Leaves for Treatment and Prevention of Breast Engorgement. 2015. Available from: http://www.breastfeed ingonline.com/cabbage.shtml\#sthash.4FMU5VUL.dpbs. Accessed at 25 October 2015.

[21] Sousa LD, Haddad ML, Nakano AMS, et al. A non-pharmacologic treatment to relieve breast engorgement during lactation: an integrative literature review. Revista da Escola de Enfermagem da USP. 2012; 46(2): 472-479.

[22] Quirino LDS, Oliveira JDD, Figueiredo MDFER, et al. Significado da experiência de nãoamamentarrelacionadoàsintercorrênciasmamárias. Cogitareenferm. 2011; 16(4): 628-633.

[23] United Health care. Breast-feeding nipple \& breast care. 2012. Available from: http://www.healthy-pregnancy.com/UHC/after _delivery/423. shtml. Accessed at 24 October 2015.

[24] Wilson-Clay B. Relieving and Treating Engorged Breasts. 2015. Available from: http://www.medelabreastfeedingus.com/ tips-and-solutions/47/relieving-and-treating-engor ged-breasts. Accessed at 24 October 2015.

[25] Davis M. Engorgement: The Cabbage Cure. 2014; Available from: http://www.lactationconsultant.info/cabbagecu re.html. Accessed at 24 October 2015.

[26] Academy of Breastfeeding Medicine Protocol Committee. ABM Protocols. ABM clinical protocol\# 20: engorgment. BREASTFEEDING MEDICINE. 2009; 4(2). Mary Ann Liebert, Inc.

[27] Polit DF, Beck CT. Essentials of nursing research. 2013. Appraising evidence for nursing practice. Lippincott Williams \& Wilkins.

[28] Hill PD, Humenick SS. The occurrence of breast engorgement. Journal of Human Lactation. 1994; 10(2): 79-86. http://dx. doi .org $/ 10.1177 / 089033449401000212$

[29] Gift AG. Validation of a vertical visual analogue scale as a measure of clinical dyspnea. Rehabilitation Nursing. 1989; 14(6): 323-325. ht tp://dx.doi.org/10.1002/j.2048-7940.1989.tb01129.x

[30] Jensen D, Wallace S, Kelsay P. LATCH: a breastfeeding charting system and documentation tool. Journal of Obstetric, Gynecologic, \& Neonatal Nursing. 1994; 23(1): 27-32. http://dx.doi.org/1 $0.1111 / j .1552-6909.1994 . t b 01847 . x$

[31] Disha AR, Singh A, Suri V. Effect of chilled cabbage leaves vs. hot compression on breast engorgement among post natal mothers admitted in a tertiary care hospital. Nursing and Midwifery Research. 2015; 11(1): 24.

[32] Resmy V, Nalini SJ, Sumath G. Effect of Lukewarm Water Compress On Prevention Of Nipple Pain And Breast Engorgement Among Primiparous At A Selected Hospital In Chennai. Journal of Science. 2014; 4(10): 620-624.

[33] Mangesi L, Dowswell T. Treatments for breast engorgement during lactation. 2010. The Cochrane Library.

[34] Wong BB, Koh S, Hegney DG, et al. The effectiveness of cabbage leaf application (treatment) on pain and hardness in breast engorgement and its effect on the duration of breastfeeding. The JBI Database of Systematic Reviews and Implementation Reports. 2012; 10(20): 1185-1213.

[35] Eapen SS, Fernandes P. Effectiveness of an Information Booklet On Home Remedial Measures For Breast Engorgement. Nitte University Journal of Health Science. 2013; 3(3).

[36] Hawkins T. Preparing Mothers for Breastfeeding after a Cesarean - The Educator's Role. 2014. Available from: http://www.sc ienceandsensibility.org/preparing-mothers-for-bre astfeeding-after-a-cesarean-the-educators-role/. Accessed at 23 November 2015.

[37] Gauss D. Breast Engorgement Relief. 2011. Available from: http://www . justbreastf eeding. com/engorgement/brea st-engorgement-relief. Accessed at 9 November 2015.

[38] Motee A, Ramasawmy D, Pugo-Gunsam P, et al. An assessment of the breastfeeding practices and infant feeding pattern among mothers in Mauritius. Journal of Nutrition and Metabolism. 2013.

[39] Mbada CE, Olowookere AE, Faronbi JO, et al. Knowledge, attitude and techniques of breastfeeding among Nigerian mothers from a semi-urban community. BMC Research Notes. 2013; 6(1): 552 PMid:24359943. http://dx.doi.org/10.1186/1756-0500-6 $-552$

[40] Arora S, Vatsa M, Dadhwal V. Cabbage leaves vs hot and cold compresses in the treatment of breast engorgement. Nursing Journal of India. 2009; 100(3): 52. PMid:19588654.

[41] Hilhorst J. Breast feeding problems. 2011. Available from: http://learnpediatrics.com/body-systems/neonate/b reastfeeding-problems/. Accessed at 23 Novamber 2015.

[42] Lamaze International. Beyond Cabbage Leaves - Causes and Solutions for Engorged Breasts. 2015. Available from: http://www . 
givingbirthwithconfidence.org/blog/beyond-cabbage

-leaves-causes-and-solutions-for-engorged-breasts.

Accessed at 23 Novamber 2015.

[43] Murray D. Breast Engorgement: Causes, Treatments, and Complications. How To Deal With Hard, Swollen, Painful Breasts. 2015. Available from: http://breastfeeding.about.com/od/CommonP roblems/a/Breast-Engorgement .htm. Accessed at 20 November 2015 .

[44] Najem B. Dhia Al-Deen L. Breast Feeding Problems in Primipara Mothers in Early Postnatal Period. Iraqi J. Comm. Med. July. 2011; 24(3).

[45] Arora S, Vatsa M, Dadhwal V. A comparison of cabbage leaves vs. hot and cold compresses in the treatment of breast engorgement. Indian Journal of Community Medicine: official publication of Indian Association of Preventive \& Social Medicine. 2008; 33(3): 160.
PMid:19876476. http://dx.doi.org/10.4103/0970-0218.42 053

[46] Berens P. ABM clinical protocol 20: Engorgement. Breastfeeding Medicine. 2009; 4(2): 111-3. http://dx.doi.org/10.1089/bfm .2009 .9997

[47] Sharma P. A Study to Assess Knowledge of Postnatal Mothers Regarding Breast Engorgement. International Journal of Nursing Education. 2013; 5(2): 130-132. http://dx.doi.org/10.5958/j.0 974-9357.5.2.079

[48] de Oliveira LD, Giugliani ERJ, do Espírito Santo LC, et al. Effect of intervention to improve breastfeeding technique on the frequency of exclusive breastfeeding and lactation-related problems. Journal of Human Lactation. 2006; 22(3): 315-321. PMid:16885491. http://dx.doi.org/10.1177/0890334406290221 